\title{
GIS-Based Emergency Management System on Abrupt Environmental Pollution Accidents in Counties of China
}

\author{
${ }^{\mathrm{a}}$ Hui Zhang, ${ }^{\mathrm{b}}$ Mao Liu \\ ${ }^{a, b}$ College of Environmental Science and Engineering, Urban Public Safety Research Center Nankai \\ University Tianjin, China
}

\begin{abstract}
Nowadays, more and more abrupt environmental pollution accidents have occurred in counties of China and seriously influenced the ecological security. It is important to make systematic studies on the occurrence of abrupt environmental pollution accidents in counties. Limited researches have been made on it in China, and it is almost impossible to make early warning and emergency management in time on abrupt environmental pollution accidents in counties. This paper established an efficient emergency management system on abrupt environmental pollution accidents in counties of China based on the technology of Geographic Information System (GIS). The framework, the design of its database and the functions of its modules were discussed and an example was described to show the practical use of the system. This system will support the establishment of emergency response and prevention system on abrupt environmental pollution accidents in counties of China
\end{abstract}

Index Terms: GIS; county; abrupt environmental pollution accident; emergency management system

(C) 2012 Published by MECS Publisher. Selection and/or peer review under responsibility of the International Conference on E-Business System and Education Technology

\section{Introduction}

Abrupt environmental pollution accident is one of the most serious pollution accidents. With the expansion of industrial activities and the increase of chemical categories and products in developed and developing countries, the possibility for the occurrence of abrupt environmental pollution accidents is increasing [1]. According to the public reports on environmental statistics, more and more factories have been moved to the counties during recent years in China. These factories causes great pollution to the counties, abrupt environmental pollution accidents occur frequently and the ecosystem is seriously destroyed [2].

The main abrupt environmental pollution accidents occurred in counties of China include abrupt water pollution accidents and air pollution accidents. Systematic studies have been made on abrupt environmental pollution accidents abroad [1,3-5]. China has made many studies on urban abrupt environmental pollution accidents, especially on the development of emergency plan systems and on certain abrupt environmental pollution accidents [6-12]. Besides, it is in lack of sequential inspection methods on environmental pollution in 
China and it is almost impossible to make early warning and emergency management in time on abrupt environmental pollution accidents in counties. The study on environmental emergency management in counties has just begun, so there is no support of key technologies, emergency management system, emergency response plan or emergency response organization on abrupt environmental pollution accidents.

This paper developed an emergency management system on abrupt environmental pollution accidents in counties based on Geographic Information System (GIS) and from the aspect of ecological security on counties. With this system, it can help to make loss assessment, accident simulation, emergency management, and so on. In that case, the abrupt environmental pollution accidents can be inspected, emergency response measures will be more effective and the public security can be guaranteed. It will also help to develop emergency management and prevention systems on abrupt environmental pollution accidents in counties.

\section{Methods}

Emergency management system on environmental pollution accidents in counties needs great amounts of information. These data include spatial geographical data and social-economic data and they all have spatial and temporal characteristics. Geographic Information System (GIS) has great functions of collection, management, analysis and output of spatial information and it can blend figures and database. The framework of emergency management system on abrupt environmental pollution accidents can be established based on GIS. The spatial data management and analysis functions of GIS can provide good technical support platform for the implement of the system. Information on accidents can be seamlessly integrated and well managed.

\subsection{Design of the System}

Based on computer technology and GIS, this paper developed an emergency management system on abrupt environmental pollution accidents, including basic database (including historical database, background database, assessment database, and so on), methods and models database, graphics database, emergency plans database, results display and query database.

With the support of GIS technology, database technology, multimedia technology and virtual reality technology, the research results can be visualized. The information on loss assessment results, accidents simulation and emergency response measures can be shared and applied to related departments and governments timely, exactly, authoritatively and dramatically.

\subsection{Platform of the System}

This system is developed based on the Window XP operation system, and uses the products of ESRI Company, such as ArcGIS Engine, ArcSDE and so on. The database system is built upon SQL Server2000, and the developing tool is Microsoft C\#. The followings are the main application flow charts of the system (Fig.1, Fig.2). 


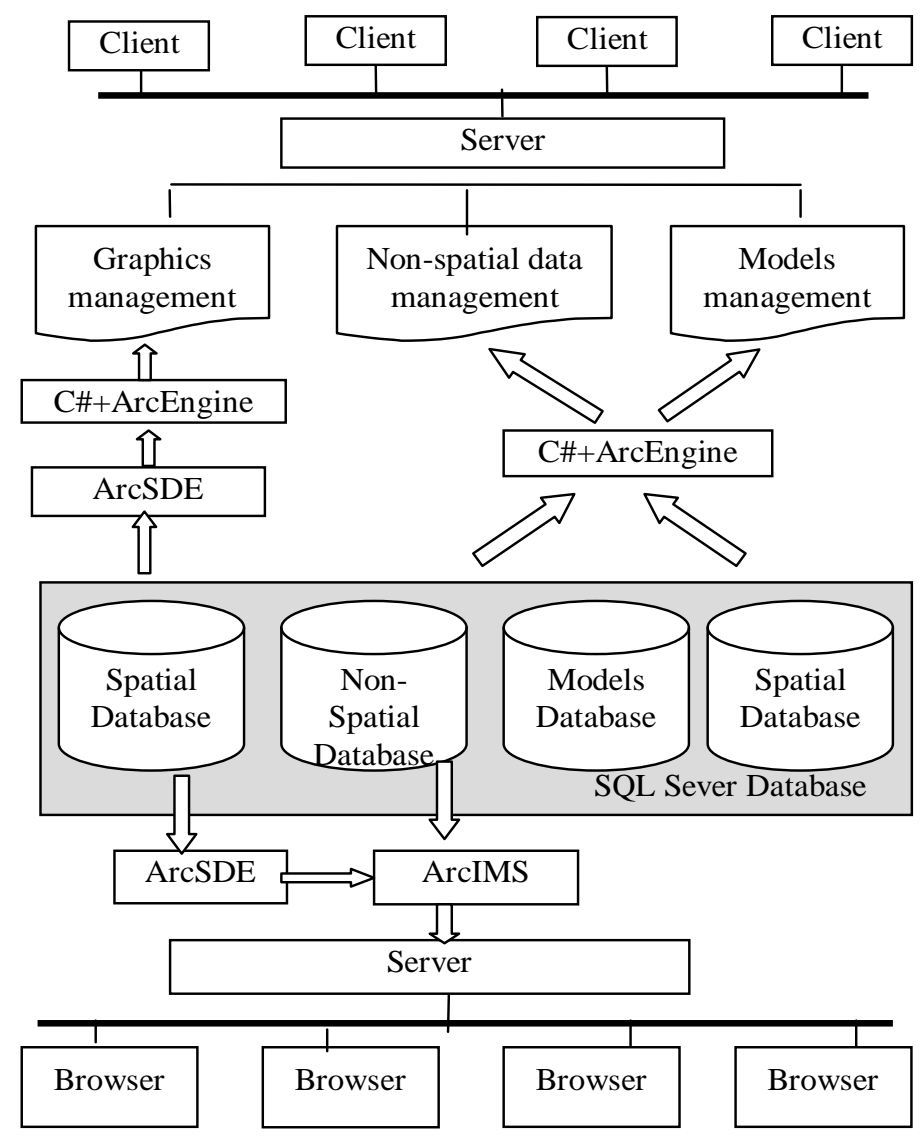

Figure 1. Framework of Emergency Management System on Abrupt Environmental Pollution Accidents in counties, China

\subsection{Design of Database}

When making emergency management on abrupt environmental pollution accidents in counties of China, it is necessary to get its social-economic information in detail and exactly. So this system chooses the administrative map of Xinzhuang Town, Changshu City, Jiangsu Province with the scale of 1:200,000 as the basic map, and a vector map of counties is built.

When the system is operated, layered data can be overlay to form the background map, and based on monitoring results, scene of accidents is displayed on the map. Then emergency management and spatial analysis such as distance analysis, area analysis, route analysis and buffer analysis on abrupt environmental pollution accidents in counties are made. 


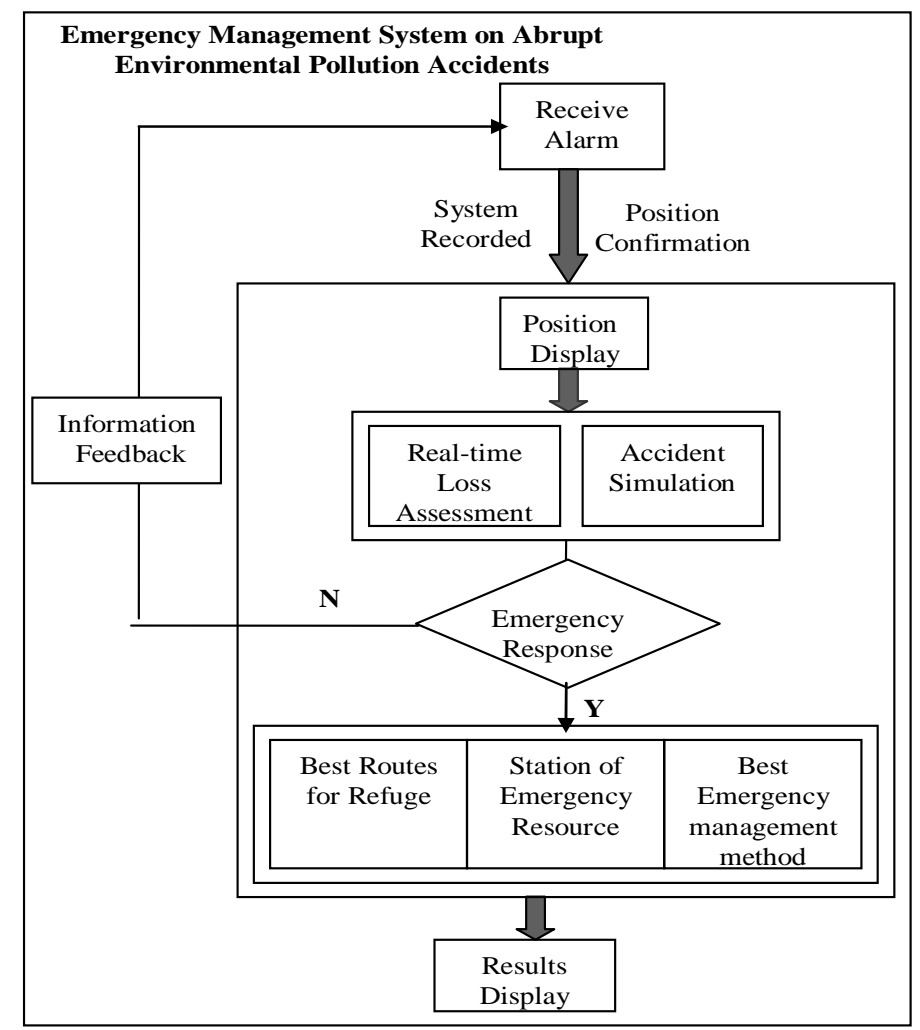

Figure 2. Flows of Emergency Management System on Abrupt Environmental Pollution Accidents in counties, China

Layers include: 1) residential areas, enterprises and other point objects; 2) medical treatment organizations, rescue centers and other point objects; 3) roads, rivers and other line objects; 4) buildings, factories and other polygon objects. Because of fast development of counties, the locations of some objects may be changed, so short-term update must be promised.

Besides, non-spatial data, such as the county's population density, property allocation, emergency rescue vehicles and instruments, and simulation models on abrupt environmental pollution accidents should also be input in the system.

Based on the characteristics of the data needed in the system, this system uses database management system such as SQL Sever 2000 as the background database. This system has the functions of storing and managing attributes and spatial data, sharing data among departments, dealing with data, maintaining the system, outputting results, and so on. The database for this system is divided into four sub-databases (Fig. 1): spatial database, non-spatial database, models database and temporal database. Spatial database can store figures, images and maps, such as remote sensing images, thematic maps, regionalized maps, risk assessment maps on abrupt environmental pollution accidents, and so forth. Non-spatial database stores historical accidents data, environmental background data and regional social-economic data (such as the property, population density, the amounts and categories of emergency response resources, and so on). Models database stores loss assessment models, resource optimizing allocation models, accident simulation software models and so on. Temporal database is used to store data produced when operating the system and the users can not see it. Spatial data and non-spatial data can associate with each other. With the organization of program, they can be integrated with the models and the functions of the system can then be carried out. 


\subsection{Function modules in the system}

The system is divided into seven modules, including files operation module, data collection module, layered display module, thematic maps query module, abrupt environmental pollution accidents models module, accidents simulation module and emergency plans query module. These modules are separated to each other on the screen, but they are connected to each other from the point of logical framework and database.

Files operation module includes the function of opening files, database connection, printing, print review, and so on. Data collection module can support the system to quickly collect basic data on the study area in time. Layered display module includes the function of adding layers, decreasing layers, zooming, legend display, overlay display, eagle eye, map output, and so on. Thematic maps query module supports the query on thematic maps, e.g. influence areas caused by abrupt environmental pollution accidents, accidents simulation maps. Abrupt environmental pollution accidents models module can use existing models to calculate the results caused by abrupt environmental pollution accidents. With this module, it can easily get the pollution concentration in different area. Accidents simulation module mainly uses the abrupt environmental pollution accidents models to simulate pollution situation and display the results visualized on electronic maps. Accident status under any possible situation can be simulated. With this module, clients can know about the accident visually. It can support the governments to make emergency response as early as possible. Emergency plans

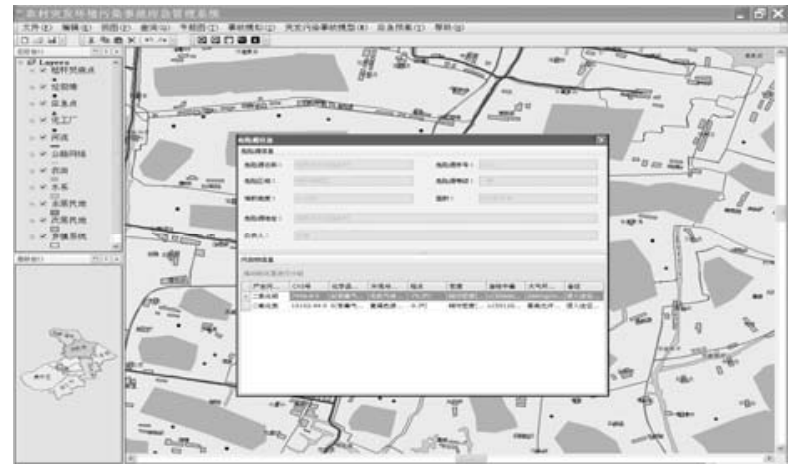

Figure 3. Dangerous source queries on abrupt air pollution accidents in counties of China

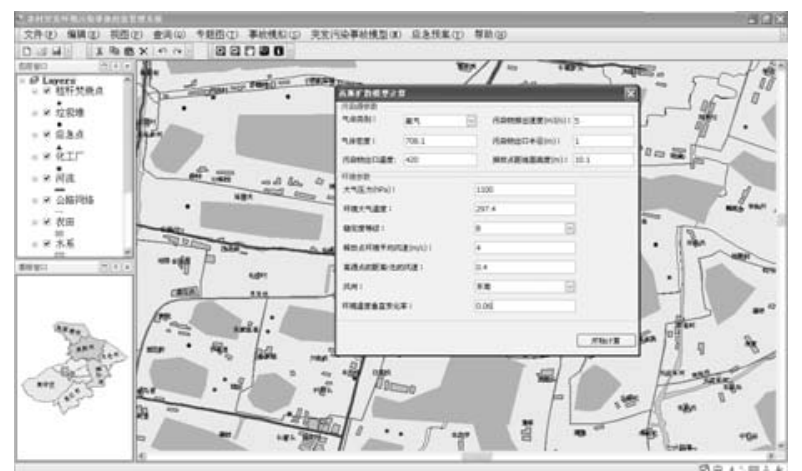

Figure 4. A simulation on abrupt air pollution accidents in counties of China

query module is mainly used to query emergency plans and emergency management measures on any environmental pollution accidents in counties. 


\section{Practical usage}

In order to show the practical use of the system, we describe how the simulation module works, and the procedure is as follows:

\section{1 Choose a Type of Environmental Pollution Accident}

Choose a dangerous source, then assign a type of abrupt environmental pollution accidents in the study area and get the basic information of the dangerous source. Here, an abrupt air pollution accident caused by leakage of ammonia storages in a factory of Xinzhuang Town (Fig. 3).

\section{2 Choose a Simulation Method}

Choose simulation method of abrupt air pollution, input data , and press the button "begin” (Fig. 4).

\section{3 Simulation Result}

Show the simulation result on the map (Fig.5, Fig.6). From the simulation result, it is easy to find that the ammonia spreads from the chemical factory to the northwest of Xinzhuang Town. Ammonia concentration near the chemical plant is at its maximum and the maximum concentration is $148.8 \sim 170.1 \mathrm{mg} / \mathrm{m}^{3}$. According to the hazardous standard of Ammonia (table 1) [13], people near the chemical factory will be moderately affected within 30min. Their breath and pulse

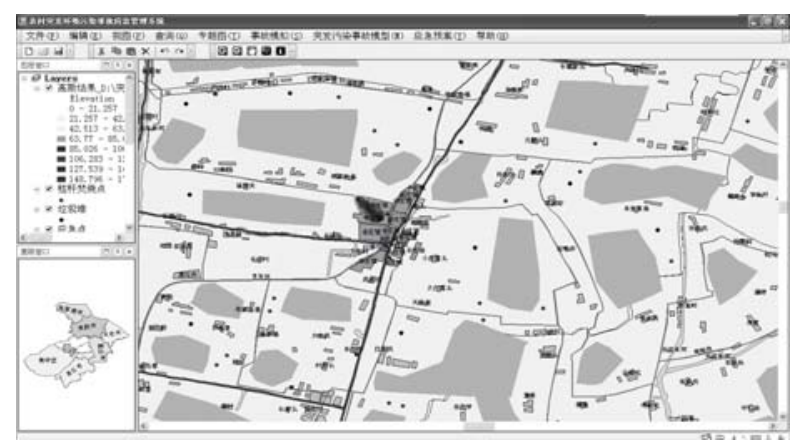

Figure 5. Simulation result on abrupt air pollution accidents in counties of China (a)

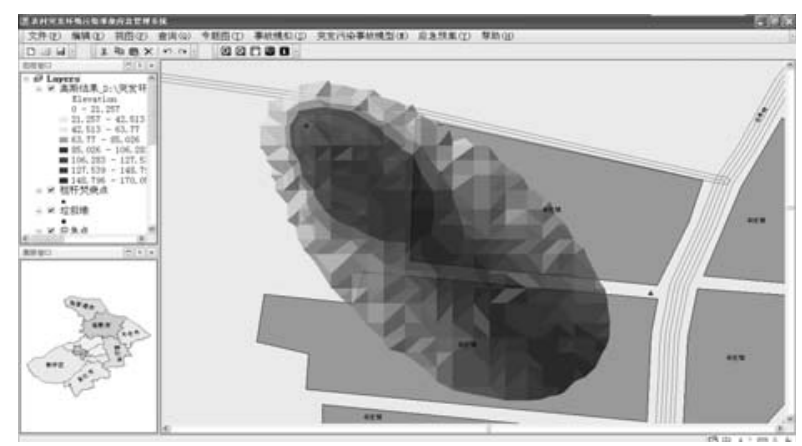

Figure 6. Simulation result on abrupt air pollution accidents in counties of China (b) 
will speed up, eyes and noses will be stimulated and these people will feel obviously uncomfortable. When ammonia spreads to the edge of Xinzhuang Town, its concentration reaches $127.5 \mathrm{mg} / \mathrm{m}^{3}$, people around this area will be lightly affected within 30min. Their breath will slow down, eyes and upper respiratory tract will be stimulated and they will be obviously uncomfortable. People stay at the area between the chemical factory and the first street of Xinzhuang Town that is about $800 \mathrm{~m}$ away from the chemical factory will be obviously affected by ammonia.

TABLE I.

DANGEROUS CONCENTRATION OF AMMONIA

\begin{tabular}{|c|c|l|}
\hline $\begin{array}{c}\text { Concentration of } \\
\text { ammonia in the air } \\
\left(\mathbf{m g} / \mathbf{m}^{\mathbf{3}}\right)\end{array}$ & $\begin{array}{c}\text { Contact Time } \\
\text { (min) }\end{array}$ & \multicolumn{1}{|c|}{$\begin{array}{c}\text { Short Term Exposure Limit } \\
\text { (STEL) }\end{array}$} \\
\hline 30 & 30 & Almost no effect \\
\hline $70-140$ & 28 & $\begin{array}{l}\text { People around the area will feel sick, } \\
\text { their breath will slow down, and their } \\
\text { eyes and upper respiratory tract will be } \\
\text { uncomfortable (Light) }\end{array}$ \\
\hline $210-350$ & 30 & $\begin{array}{l}\text { People around the area will feel } \\
\text { obviously uncomfortable, their breath } \\
\text { and pulse will speed up, and eyes and } \\
\text { noses will be stimulated (Moderate })\end{array}$ \\
\hline 700 & 30 & $\begin{array}{l}\text { People around the area will cough } \\
\text { immediately and will be strongly } \\
\text { stimulated } \\
\text { (Moderate) }\end{array}$ \\
\hline $1750-4500$ & 30 & $\begin{array}{l}\text { People around the area will die } \\
\text { immediately (Severe) }\end{array}$ \\
\hline
\end{tabular}

So after querying the emergency plan of abrupt air pollution in the emergency management system of abrupt environmental pollution accidents on counties emergency management measures can be made: a) people around the pollution area should be evacuated and the area must be isolated immediately; b) People is not allowed in and all fire source must be cut off; c) emergency personnel should take on the gas masks and protective clothing and cut off the leakage source if possible; d) keep ventilation to accelerate the diffusing ammonia; e) spray low concentration hydrochloric acid at the high concentration area to counteract, dilute and dissolve ammonia; f) build banks or dig trenches to store the wastewater; and g) the ammonia container should be used after reparation and severe proof.

\section{Conclusions}

This paper established an emergency management system on abrupt environmental pollution accidents in counties based on GIS. The system mainly has the functions of data collection, thematic maps query, abrupt environmental pollution accidents calculation, accidents simulation and emergency plans query. An abrupt air pollution accident caused by leakage of ammonia storages in a factory of Xinzhuang Town was analyzed in the system to show the practical use of the system. This system is an integrated system. With the development of accident models and simulation technologies on abrupt environmental pollution accidents, it can reduce emergency response time and improve the efficiency. It also provides great supports for timely, quick and exact emergency management in counties of China. This system is established on practical application and can be used widely. 


\section{References}

[1] A. V.K., Measuring the benefits of clean air and water, China Zhanwang Press, Beijing, 1989. (in Chinese)

[2] C.F. Tong, Y.X. Yang, Rural Industrialization and Primary Investigation on its Causes for Environmental Pollution in China, Journal of Jiangnan University(Humanities \& Social Sciences Edition), 2009,8(3), pp. 37-41. (in Chinese)

[3] Eric M., W. Sieglein., Security Planning and Disaster Recovery, Posts and Telecom Press, Beijing, 2003. (in Chinese)

[4] John A.D., L. F. Scylla, and R.A. Carpenter, Economic Analysis on Environmental Influence, China Environmental Science Press, Beijing, 2001. (in Chinese)

[5] M. Gradinscak, V. Beck, and P. Brennan, 3D Computer Modeling and Human Response, Fire and Material, 1999, 23, pp. 389-393.

[6] K. X. Zhan, G.H. Chen, Discussion on the Establishment of Inter-city Disaster Emergency Management System and its Key Issues, China Safety Science Journal, 2009, 19(9), pp. 172-176. (in Chinese)

[7] D.H. Liu, M. Liu, and C.X. Ren, Estimating Water Pollution Risk Arising from Road Accidents, Journal of Safety and Environment, 2008, 8(6), pp. 140-143. (in Chinese)

[8] Z. M. Li, D. Lv, Research and Development of Assessment System for Calculating the Risk Area of Toxic Gas Leaking, Petrochemical Safety and Environmental Protection Technology, 2007, 23(2), pp, 27-28. (in Chinese)

[9] B. Zhang, Q. Wang, and S. Li, S."The system dynamics based research of water quality simulation in the Songhua River water pollution accident”, Proceedings of the 2007 Conference on Systems Science, Management Science and System Dynamics: Sustainable Development and Complex Systems, 2007, pp. 2797-2804.

[10] Y. Liu, P. Yin, and C. Shi, "the development and research of Geographical Information System of Marine Oil Spill Emergency Response”, Proceedings of the 2001 International Conference on Science and Engineering, 2001, pp. 425-429.

[11]L. Yong, H.P. Sharma, “A GIS approach to managing gaseous hazardous spills on highways”, GIS/LIS '95 Annual Conference and Exposition, 1995, 2, PP. 581-590.

[12] N. B. Chang; J. H. Chou; and H.Y. Yang, the environmental diagnosis and supervision mobile system for emergency cases, Journal of Taipower's Engineering, 2001,640, pp. 80-109. (in Chinese )

[13] Y. Wang, Z.W. Gu , and S. Zhang, Modern Occupational Medicin, Beijing:People’s medical publishing house, 1996, pp.642-645. (in Chinese) 